\title{
Effects of substrate and anode metal annealing on InGaZnO Schottky diodes
}

DOI:

$10.1063 / 1.4973693$

Document Version

Accepted author manuscript

Link to publication record in Manchester Research Explorer

\section{Citation for published version (APA):}

Du, L., Li, H., Yan, L., Zhang, J., Qian Xin, Qingpu Wang, \& Song, A. (2017). Effects of substrate and anode metal annealing on InGaZnO Schottky diodes. Applied Physics Letters, 110, [011602]. https://doi.org/10.1063/1.4973693

\section{Published in:}

Applied Physics Letters

\section{Citing this paper}

Please note that where the full-text provided on Manchester Research Explorer is the Author Accepted Manuscript or Proof version this may differ from the final Published version. If citing, it is advised that you check and use the publisher's definitive version.

\section{General rights}

Copyright and moral rights for the publications made accessible in the Research Explorer are retained by the authors and/or other copyright owners and it is a condition of accessing publications that users recognise and abide by the legal requirements associated with these rights.

\section{Takedown policy}

If you believe that this document breaches copyright please refer to the University of Manchester's Takedown Procedures [http://man.ac.uk/04Y6Bo] or contact uml.scholarlycommunications@manchester.ac.uk providing relevant details, so we can investigate your claim.

\section{OPEN ACCESS}


This manuscript was accepted by Appl. Phys. Lett. Click here to see the version of record.

fects of Substrate and Anode Metal Annealing on InGaZnO Schottky Diodes

\title{
Lulu Du, ${ }^{1, a)} \mathrm{He} \mathrm{Li},{ }^{1, a)}$ Linlong Yan, ${ }^{1}$ Jiawei Zhang, ${ }^{2}$ Qian Xin, ${ }^{1, b)}$ Qingpu Wang, ${ }^{1}$ and Aimin Song ${ }^{2, b)}$
}

\author{
${ }^{1}$ Center of Nanoelectronics and School of Microelectronics, Shandong University, Jinan 250100, China \\ ${ }^{2}$ School of Electrical and Electronic Engineering, University of Manchester, Manchester M13 9PL, United \\ Kingdom
}

By studying different annealing effects of substrate and anode metal, high-performance Schottky diodes based on InGaZnO (IGZO) film have been realized. It is observed that a suitable thermal annealing of the $\mathrm{SiO}_{2} / \mathrm{Si}$ substrate significantly improves the diode performance. In contrary, annealing of the Pd anode increases surface roughness, leading to degradation in the diode performance. As such, by only annealing the substrate but not the anode, we are able to achieve an extremely high rectification ratio of $7.2 \times 10^{7}$, a large barrier height of $0.88 \mathrm{eV}$, and a near unity ideality factor of 1.09 . The diodes exhibit the highest performance amongst IGZO-based Schottky diodes reported to date where IGZO layer is not annealed. The capacitance vs. voltage measurements indicate that the surface roughness is correlated with the trap state density at the Schottky interface.

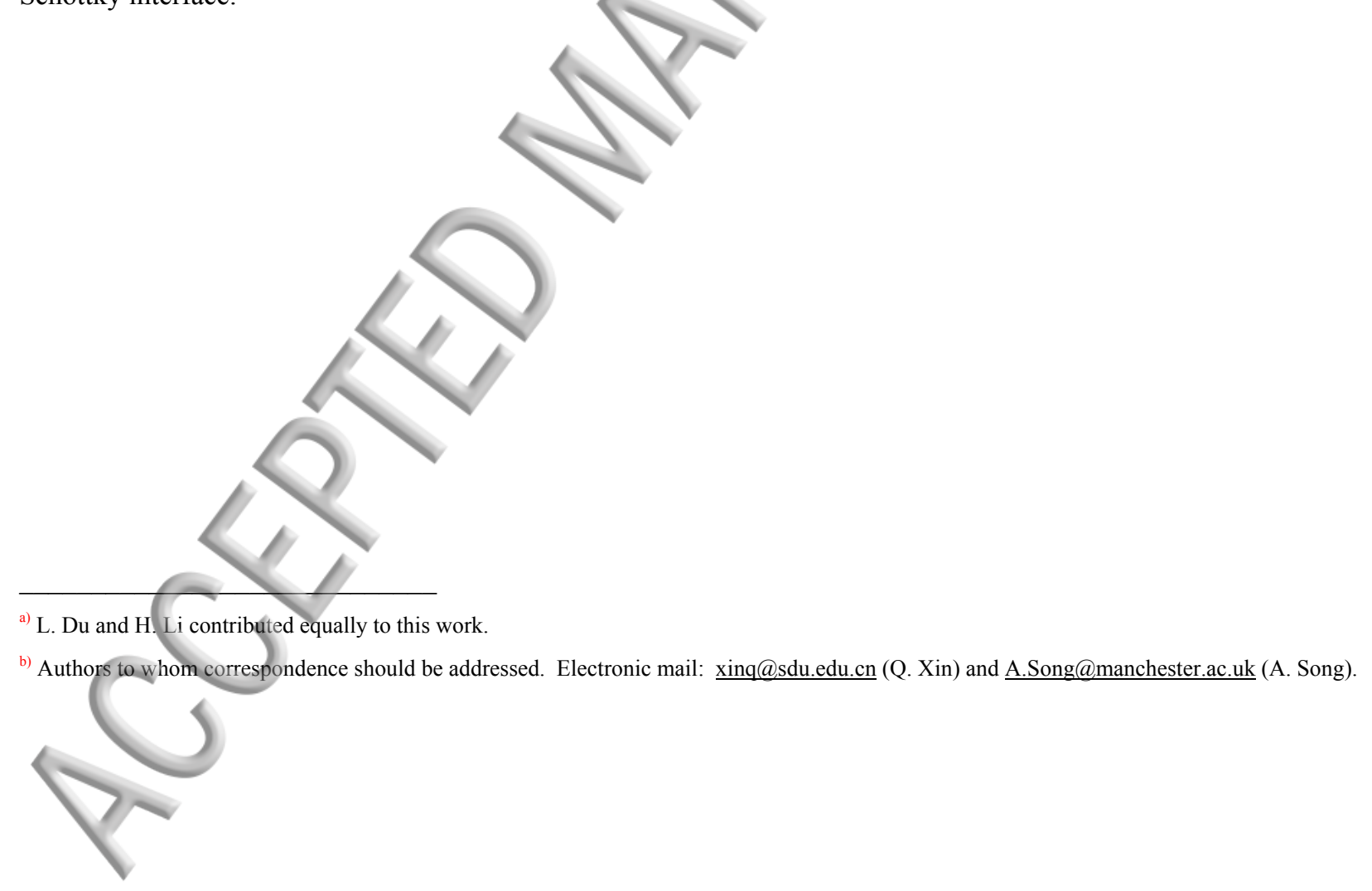


morphous oxide semiconductors represented by InGaZnO (IGZO) have superior characteristics to amorphous silicon due to their high carrier mobilities, low-temperature deposition, and excellent uniformity owing to their amorphous nature. Most studies on IGZO so far have focused on thin-film transistors (TFTs). TFTs with higher performance than conventional amorphous silicon transistors have been developed ${ }^{1,2}$ after intensive studies and improvements on carrier transport ${ }^{3-5}$ and stability. ${ }^{6-8}$ In contrast, very limited studies have been reported on IGZO-based Schottky diodes. A major challenge is the difficulty in forming stable and ideal Schottky contacts on oxide semiconductors, because the surface of oxide semiconductors is known to be sensitive to device fabrication processes and atmospheric exposure. The limited studies on IGZO Schottky diodes have been focused on achieving large barrier heights, $\widetilde{\Phi}_{\mathrm{B}},{ }^{910}$ high rectification ratios, $I_{\mathrm{on} / \mathrm{off}}{ }^{9,11,12}$ low ideality factors, $n, n^{9,10,13}$ and high-frequency operation. ${ }^{11,12,14}$ So far, thermal annealing at $\sim 200{ }^{\circ} \mathrm{C}$ has been used in most studies. The best annealed diodes fabricated by using the sputtering technique showed an $I_{\text {on/off }}$ of $\sim 10^{8}, \Phi_{\mathrm{B}}$ of $\sim 0.9 \mathrm{eV}$, and $n$ of $\sim 1.2 .^{11,12}$ In the case of annealed diode based on an IGZO layer grown by pulsed laser deposition technique, the best ideality factor reached 1.04. ${ }^{9}$ However, thermal annealing at high temperatures is not preferred when fabricating low-cost, flexible diodes on substrates such as polyethylene terephthalate (PET). Recently, we reported as-deposited IGZO diodes on glass substrate that achieved an ideality factor of $1.14 .{ }^{15}$ Such an ideality factor is even lower than the value obtained by the annealed devices deposited using similar sputtering techniques mentioned above. It is therefore interesting to study how exactly annealing at different stages of the device fabrication may affect the device performance. So far, thermal annealing of IGZO Schottky diodes was generally performed on the whole device after the final device fabrication step, ${ }^{9,12}$ and in some cases additional annealing was carried out on the IGZO layer itself. ${ }^{10,11,13}$ Here, we first annealed the $\mathrm{SiO}_{2} / \mathrm{Si}_{\text {substrate before }}$ depositing any diode layer, and observed an improvement in diode performance. In contrast, thermal annealing on the Pd anode produced an adverse effect on the diode performance.

$\mathrm{SiO}_{2} / \mathrm{Si}$ wafers were used as the substrates and they were sequentially cleaned in an ultrasonic bath of decon, de-ionized water, acetone, and ethanol and dried by $\mathrm{N}_{2}$. A 3-nm-thick Ti layer was deposited on the substrate for adhesion. A 47-nmthick Pd layer was deposited as anode electrode, and then treated with oxygen plasma (PDC-32G, 10 min) for oxidation and to ensure good oxygen stoichiometry of the contact interface prior to IGZO deposition. ${ }^{11,16}$ To study the effect of thermal treatment of $\mathrm{SiO}_{2} / \mathrm{Si}$ substrate and Pd anode on the device performance, a hotplate (Model p-10, POLISH Co.) was used to anneal the samples in ambient air. A 100-nm-thick IGZO layer was deposited by radio-frequency (RF) magnetron sputtering at room temperature with an $\mathrm{InGaZnO}_{4}$ ceramic target (In:Ga:Zn $=1: 1: 1$ in atomic ratio, Lesker Co.). The $\mathrm{RF}$ sputtering power was $70 \mathrm{~W}^{15,17,18}$ and the mixed gas was argon with $2.5 \%$ oxygen. ${ }^{15,17}$ The working pressure was 3.6 mTorr. Finally, $\mathrm{Ti}(40 \mathrm{~nm}) / \mathrm{Au}(40 \mathrm{~nm})$ was deposited as top ohmic contact with a shadow mask. All the metals were deposited by electron- 

measurements using an Agilent E2902B semiconductor analyzer and an Agilent E4980A LCR meter, respectively, at room temperature. The morphology of the Pd and the IGZO thin films were investigated using an atomic-force microscope (AFM, Dimension FastScan $\left.{ }^{\mathrm{TM}}\right)$.

The $J-V$ curves of the fabricated Schottky diodes were analyzed using standard theory of thermionic emission of majority carriers over the junction barrier, ${ }^{19}$

$$
J=A^{*} T^{2} \exp \left(\frac{-q \Phi_{B, J V}}{k T}\right)\left(\exp \left[\frac{q\left(I-R_{S}\right)}{n k T}\right]-1\right)
$$

where $q$ is the element charge, $R_{\mathrm{S}}$ is the series resistance, $k$ is the Boltzmann constant, $A^{*}$ is the effective Richardson constant which is $41 \mathrm{Acm}^{-2} \mathrm{~K}^{-2}$ for IGZO, ${ }^{3}$ and $\Phi_{\mathrm{B}, J V}$ is the effective barrier height measured by $J-V$ characteristics.

The capacitance of a Schottky junction is given by, ${ }^{19}$

$$
\frac{A^{2}}{C^{2}}=\left(\frac{2}{q \varepsilon_{s} \varepsilon_{0} N_{d e p l}}\right)\left(V_{b i}-\frac{k T}{q}-V\right)
$$

where $A$ is the active area of the diode, $\varepsilon_{\mathrm{s}}$ is the static dielectric constant of the semiconductor, $\varepsilon_{0}$ is the dielectric constant of vacuum, $V_{\mathrm{bi}}$ is the built-in potential, and $N_{\text {depl }}$ is the background doping density in the depletion region.

Figure 1 shows the $J-V$ curves of IGZO/Pd Schottky diodes with and without thermal annealing at different stages of the device fabrication. For Sample A, the $\mathrm{SiO}_{2} / \mathrm{Si}$ substrate was annealed at $300{ }^{\circ} \mathrm{C}$ for $30 \mathrm{~min}$ but the $\mathrm{Pd}$ anode was not annealed; Sample B: the $\mathrm{SiO}_{2} / \mathrm{Si}$ substrate was annealed at $300{ }^{\circ} \mathrm{C}$ for $30 \mathrm{~min}$, and after deposition of $\mathrm{Pd}$ on the substrate, the sample was annealed at $230^{\circ} \mathrm{C}$ for $60 \mathrm{~min}$; Sample C: neither the substrate nor the anode was annealed; Sample D: the $\mathrm{SiO}_{2} / \mathrm{Si}$ substrate was not pre-annealed but after deposition of $\mathrm{Pd}$, the sample was annealed at $230{ }^{\circ} \mathrm{C}$ for $60 \mathrm{~min}$. It has been found that water molecules bonded to the silanol groups of $\mathrm{SiO}_{2} / \mathrm{Si}$ substrate can be desorbed via annealing at $220{ }^{\circ} \mathrm{C},{ }^{20}$ thus the substrate annealing at $300{ }^{\circ} \mathrm{C}$ removes moisture and organic adsorbates, thereby improving the uniformity of substrate surface and adhesion of $\mathrm{Pd}$ anode.

As can be seen in Fig. 1, at an applied voltage of $1 \mathrm{~V}$, the on-current densities $\left(J_{\text {on }}\right)$ of the four samples are of the order of $10^{\circ} \mathrm{A} / \mathrm{cm}^{2}$ with $R_{\mathrm{s}}$ in the range of $0.06 \sim 0.08 \Omega . \mathrm{cm}^{2}$. In contrast, at an applied voltage of $-1 \mathrm{~V}$, the off-current densities $\left(J_{\text {off }}\right)$ show clear dependence on the process conditions, resulting in significant differences in $I_{\text {on/off }}$ ratios. Sample A, fabricated with annealed $\mathrm{SiO}_{2} / \mathrm{Si}$ and as-deposited Pd anode, exhibits the highest performance with an $I_{\text {on/off }}$ of $7.2 \times 10^{7}$, a $\Phi_{\mathrm{B}, J V}$ of $0.88 \mathrm{eV}$, and a near unity $n$ of 1.09 . Using Eq. (1), the extracted $\Phi_{\mathrm{B}, J V}$ are $0.88,0.86,0.85$, and $0.77 \mathrm{eV}$, for samples 
and D, respectively, as shown in Table 1, which could partly explain the differences in $J_{\text {off. }}$ All four samples show samples $\mathrm{A}$ and $\mathrm{C}$ shows that the substrate annealing enhances $\Phi_{\mathrm{B}}$ by about $30 \mathrm{meV}$ and enables a decrease of one order of magnitude in $J_{\text {off. }}$ In order to further evaluate the surface morphology, AFM characterization has been performed. The results show that the as-deposited Pd films on annealed and unannealed $\mathrm{SiO}_{2} / \mathrm{Si}$ substrates (Samples $\mathrm{A}$ and $\mathrm{C}$ ) exhibit RMS roughnesses of 0.69 and $0.75 \mathrm{~nm}$, respectively, as shown in Figs. 2(a) and (c). However, a comparison of samples A and B shows that Pd annealing contributes to a slight degradation in device performance, with $I_{\mathrm{on} / \text { off }}$ and $\Phi_{\mathrm{B}, J V}$ decreasing from $7.2 \times$ $10^{7}$ to $3.5 \times 10^{7}$ and 0.88 to $0.86 \mathrm{eV}$, respectively. This is correlated to an increase in Pd RMS roughness from 0.69 to 0.73 $\mathrm{nm}$ after annealing of the Pd anode, as shown in Figs. 2(a) and (b). The thermal expansion coefficient value is $5.2 \times 10^{5}{ }^{\circ} \mathrm{C}^{-1}$ for $\mathrm{SiO}_{2}{ }^{21}$ and is $1.2 \times 10^{7} \mathrm{C}^{-1}$ for $\mathrm{Pd}^{22}$. The latter is about 23 times higher, which induces large stresses in the $\mathrm{SiO}_{2} / \mathrm{Pd}$ interface during the heating up and cooling down processes. This could increase the surface roughness of Pd surface as well as the Pd/IGZO interface. ${ }^{23}$ Furthermore, desorption of water molecules bonded to the silanol groups of $\mathrm{SiO}_{2} / \mathrm{Si}_{\text {substrate }}$ by thermal annealing of the substrate is expected to improve the uniformity and surface roughness of $\mathrm{SiO}_{2} / \mathrm{Si}$ substrate and perhaps more importantly strengthens the adhesion of $\mathrm{Pd}$ layer, resulting in sample A having the lowest $\mathrm{Pd}$ surface roughness. Although sample D appears to have a slightly low RMS roughness than sample C, the difference is only $0.02 \mathrm{~nm}$, as shown in Figs. 2(c) and (d), which is within the measurement error range of the AFM that we used. In our experiments, we have fabricated a large number of devices (about 4) under each of the four conditions, and the $J-V$ and surface roughness results are consistent among these devices.

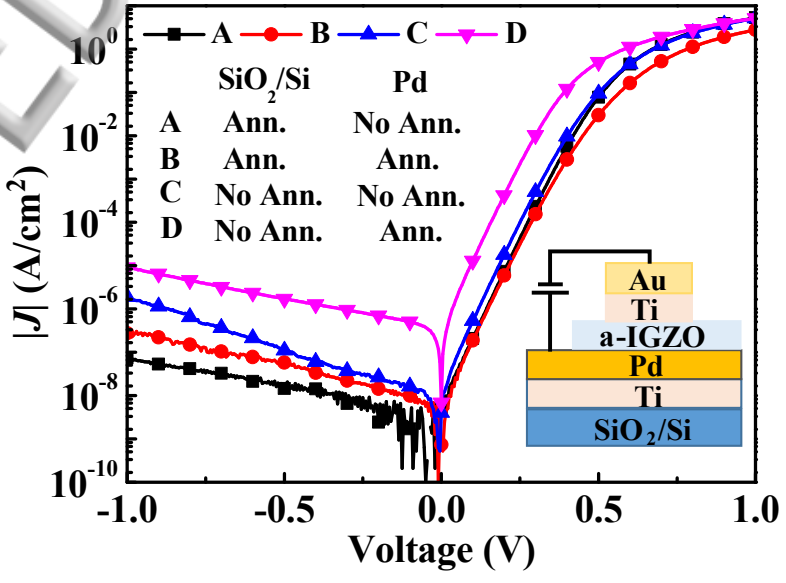

Fig. $1 \mathrm{~J}-\mathrm{V}$ characteristics of the as-deposited IGZO/Pd Schottky diodes on annealed (Ann.) and unannealed (No $\mathrm{Ann}$.) $\mathrm{SiO} / 2 \mathrm{Si}$ substrates and with annealed (Ann.) and unannealed (No Ann.) Pd anodes. The annealing conditions are $300{ }^{\circ} \mathrm{C} / 30 \mathrm{~min}$ for $\mathrm{SiO} / 2 \mathrm{Si}$ and $230{ }^{\circ} \mathrm{C} / 60$ min for Pd. The cross-section schematic of the diode is shown in the inset.

Table 1 The root mean square (RMS) roughness of Pd anode, series resistance $\left(R_{\mathrm{s}}\right)$, ideality factor $(n)$, rectification ratio $\left(I_{\mathrm{on} / \text { off }}\right)$ at $\pm 1 \mathrm{~V}$. Schottky barrier height calculated by $J-V\left(\Phi_{\mathrm{B}, J V}\right)$ and $C-V\left(\Phi_{\mathrm{B}, C V}\right)$, and the different between two $\left(\Delta \Phi=\Phi_{\mathrm{B}, C V}-\Phi_{\mathrm{B}, J V}\right)$, built-in potential $\left(V_{\text {bi }}\right)$, background doping density $\left(N_{\text {depl }}\right)$, and free carrier concentration $\left(N_{\mathrm{e}}\right)$ for samples A, B, C and D. 


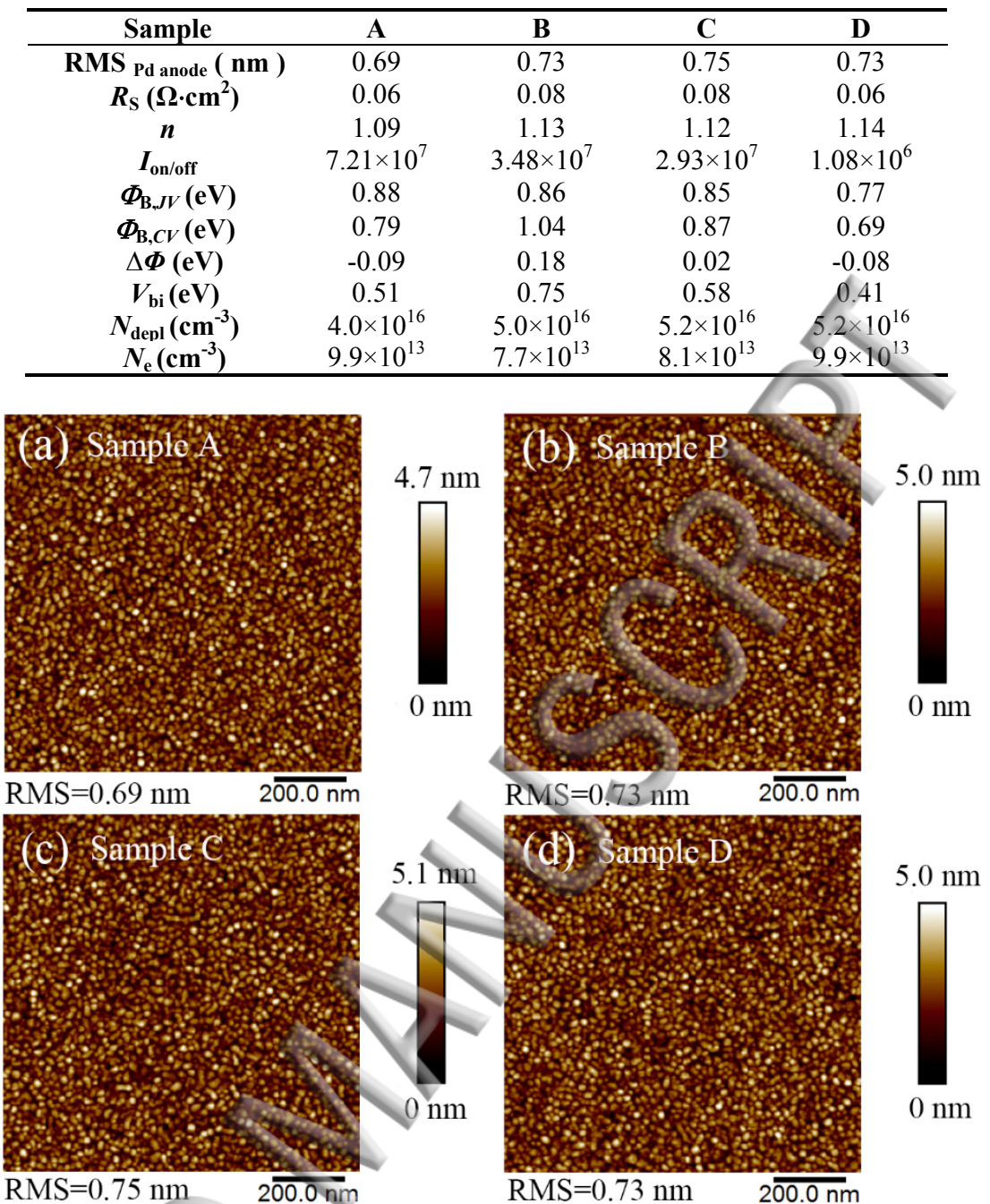

Fig. 2. AFM images and the RMS surface roughness of as-deposited (a) and annealed (b) $\mathrm{Pd}$ surfaces on annealed $\mathrm{SiO}_{2} / \mathrm{Si}$ substrates, and as-deposited (c) and annealed (d) Pd surfaces on unpreannealed $\mathrm{SiO}_{2} / \mathrm{Si}$ substrates.

Figure 3(a) shows $C-V$ characteristics of sample A in the frequency range of $1 \mathrm{kHz}$ to $1 \mathrm{MHz}$ at room temperature. It is found that the measured $C$ strongly depends on the frequency. The curves shift towards positive voltage and the measured $C$ decreases with increasing frequency due to the existence of interface traps. ${ }^{24}$ At low frequencies, the time constant permits the charge to move in and out of interface trap states in response to an applied signal, that is, an excess capacitance is induced. However, at a sufficiently high frequency, the time constant is too short for the interface trap states to respond and the excess capacitance can be neglected. ${ }^{21}$-To minimize the influence of the interface trap states on $C-V$ measurements, a high frequency of $1 \mathrm{MHz}$ was used for all four samples A, B, C and D, as shown in Fig. 3(b). The relative dielectric constant of IGZO is 17.6 as we reported previously. ${ }^{15,17}$ From the $A^{2} / C^{2}-V$ curves and Eq. (2), the built-in voltage $V_{\text {bi }}$ and $N_{\text {depl }}$ are extracted. The free charge concentration, $N_{\mathrm{e}}$, can be estimated from $R_{\mathrm{s}}$ by assuming an electron mobility of $10 \mathrm{~cm}^{2} / \mathrm{Vs}^{5,15} V_{\mathrm{bi}}$ is decreased and the $N_{\text {depl }}$ is increased in order of samples B, C, D, which results in a decrease of the depletion region 

conduction band density of states. ${ }^{25}$ The calculated values are shown in Table 1 . The discrepancy between $\Phi_{\mathrm{B}, J V}$ and $\Phi_{\mathrm{B}, C V}$, $\Delta \Phi=\Phi_{\mathrm{B}, C V}-\Phi_{\mathrm{B}, J V}$, is most likely due to the barrier inhomogeneities. ${ }^{26,27} \Phi_{\mathrm{B}, J V}$ obtained from the current-voltage measurement is rather sensitive to the barrier inhomogeneities and is more related to the regions where the barrier is the lowest. ${ }^{26}$ In contrast, $C$ - $V$ measurements give the mean barrier height which is usually smaller than $\Phi_{\mathrm{B}, J V}$ for single crystalline semiconductors with extremely low trap state densities. ${ }^{28-30}$ However, in amorphous semiconductors such as IGZO, due to the contribution of relatively large subgap trap density to the measured $C, \Phi_{\mathrm{B}, C V}$ is sometimes higher than $\Phi_{\mathrm{B}, J V}{ }^{15,16}$ The very low $|\Delta \Phi|(0.02-0.18 \mathrm{eV})$ of samples A, B, C, and D indicates a high uniformity of barrier height and high quality of the Schottky contacts, which agrees well with the low $n(\sim 1.1)$ of these diodes. The best optimized device, sample $\mathrm{A}$, has the lowest $N_{\text {depl }}$ of $4.0 \times 10^{16} \mathrm{~cm}^{-3}$ and the highest $N_{\mathrm{e}}$ of $9.9 \times 10^{13} \mathrm{~cm}^{-3}$, as shown in Table 1 . The discrepancy between $N_{\text {depl }}$ and $N_{\mathrm{e}}$ is mainly attributed to the subgap traps in amorphous semiconductor. ${ }^{11,14,16}$ Sample $\mathrm{A}$ has the lowest ratio $\mathrm{N}_{\mathrm{dep}} / \mathrm{N}_{\mathrm{e}}$ of $4.0 \times 10^{2}$, which means for each free electron, there are roughly $4.0 \times 10^{2}$ ionized atoms. This indicates that among the four samples, sample A has the lowest subgap trap density. ${ }^{16}$ As the IGZO layer in all the samples is deposited under the same condition, it is expected that their bulk trap density should be the same. Thereby, the discrepancy of subgap trap density of these samples is due to different thermal treatments of the substrate and the anode, causing different interface trap densities. The interface state density is expected to depend greatly on the interfacial roughness. ${ }^{31,32}$ Larger film roughness causes larger interfacial area, resulting in a possibility of more interface states even if their density per real interface area remains the same. ${ }^{33}$ Furthermore, the increased roughness was most likely caused by different thermal expansion coefficients, and the residual strain in the film may also lead to increased band-gap states. ${ }^{34}$ Our $C$ - $V$ and AFM results therefore suggest that sample A has both the lowest interface trap density and the smoothest Schottky anode interface. 

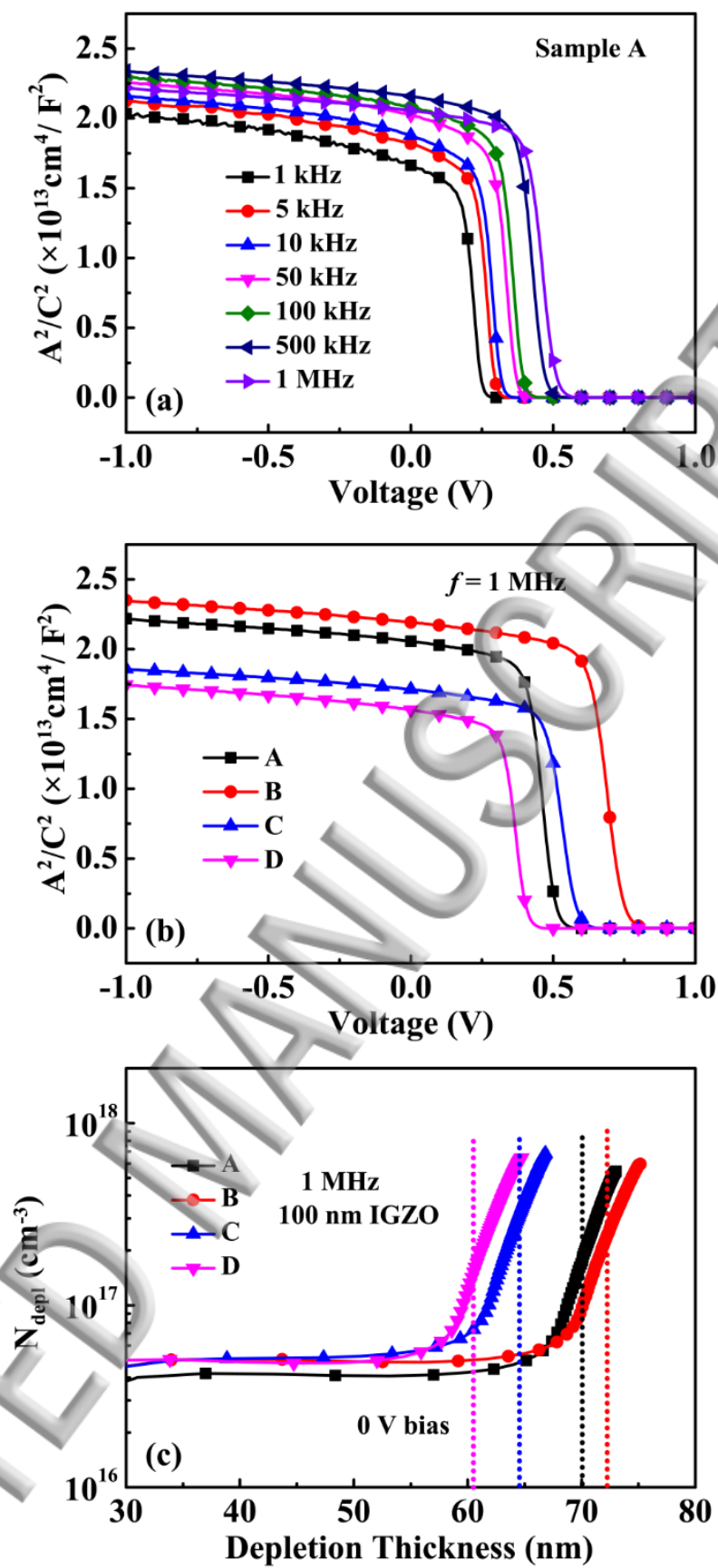

Fig. 3 (a) The capacitance-voltage ( $C$ - $V$ ) measurements of sample A at various frequencies. (b) $C-V$ curves measured at $1 \mathrm{MHz}$ of samples A, B, C and D. (c) The corresponding background doping density $\left(N_{\text {depl }}\right)$ as a function of depletion thickness. The dotted line indicates the depletion region thickness at zero bias.

In summary, by performing thermal treatment on individual layers during fabrication of IGZO Schottky diodes, we have observed a dependency of the device performance on the roughness of different layer surfaces. While thermal annealing of the $\mathrm{SiO}_{2} / \mathrm{Si}$ substrate improves the device homogeneities, an opposite effect is observed on the annealing of the Pd electrode. Furthermore, a correlation between the roughness of the Schottky contact and the interface trap state density has also been 
This work was financed by the National Key Research and Development Program of China (Grant No. 2016YFA0301200), the National Natural Science Foundation of China (Grant Nos. 11374185 and 11304180), Engineering and Physical Sciences Research Council (EPSRC) (Grant No. EP/N021258/1), China Postdoctoral Science Foundation funded project (2016M590634), the Natural Science Foundation of Shandong Province (ZR2013EMQ011), the Natural Science Foundation of Jiangsu Province (BK20151255), Suzhou Planning Projects of Science and Technology (SYG201527 and SYG201616), and the Fundamental Research Funds of Shandong University (2013TB008, 2014QY005 and 2016WLJH44).

\section{REFERENCES}

${ }^{1}$ K. Nomura, H. Ohta, A. Takagi, T. Kamiya, M. Hirano, H. Hosono, Nature, 432, 488-492 (2004).

${ }^{2}$ H. Yabuta, M. Sano, K. Abe, T. Aiba, T. Den, H. Kumomi, K. Nomura, T. Kamiya, H. Hosono, Appl. Phys. Lett., 89, 112123 (2006).

${ }^{3}$ A. Takagi, K. Nomura, H. Ohta, H. Yanagi, T. Kamiya, M. Hirano, H. Hosono, Thin Solid Films, 486, 38-41(2005).

${ }^{4}$ J.-S. Park, J. K. Jeong, H.-J. Chung, Y.-G. Mo, H. D. Kim, Appl. Phys. Lett., 92, 072104 (2008).

${ }^{5}$ T. Kamiya, K. Nomura, H. Hosono, Adv. Mat., 11, 044305 (2016).

${ }^{6}$ H. Q. Chiang, B. R. McFarlane, D. Hong, R. E. Presley, J. F. Wager, J. Non-cryst. Solids, 354, 2826-2830 (2008).

${ }^{7}$ J. Lee, J.-S. Park, Y. S. Pyo, D. B. Lee, E. H. Kim, D. Stryakhilev, T. W. Kim, D. U. Jin, Y.-G. Mo, Appl. Phys. Lett., 95, 123502 (2009).

${ }^{8}$ K. H. Ji, J.-I. Kim, H. Y. Jung, S. Y. Park, R. Choi, U. K. Kim, C. S. Hwang, D. Lee, H. Hwang, J. K. Jeong, Appl. Phys. Lett., 98, 103509 (2011).

${ }^{9}$ D. H. Lee, K. Nomura, T. Kamiya, H. Hosono, IEEE Electron Device Lett., 32, 1695-1697 (2011).

${ }^{10}$ A. Chasin, L. Q. Zhang, A. Bhoolokam, M. Nag, S. Steudel, B. Govoreanu, G. Gielen, P. Heremans, IEEE Electron Device Lett., 35, 642-644 (2014).

${ }^{11}$ A. Chasin, M.Nag, A. Bhoolokam, K. Myny, S. Steudel, S. Schols, J. Genoe, G. Gielen, P. Heremans, IEEE Tran. Electron Devices, 60, 3407-3412 (2013).

${ }^{12}$ A. Chasin, S. Steudel, F. Vanaverbeke, K. Myny, M. Nag, T. H. Ke, S. Schols, G. Gielen, J. Genoe, P. Heremans, IEEE IEDM Tech. Dig. 2012, 12.4.1-12.4.4. 
${ }^{15}$ Q. Xin, L. Yan, Y. Luo, A. Song, Appl. Phys. Lett., 106, 113506 (2015).

${ }^{16}$ A. Chasin, S. Steudel, K. Myny, M. Nag, T.-H. Ke, S. Schols, J. Genoe, G. Gielen, P. Heremans, Appl. Phys. Lett., 101, 113505 (2012).

${ }^{17}$ Q. Xin, L. Yan, L. Du, J. Zhang, Y. Luo, Q. Wang, A. Song, Thin Solid Films, 616, 569-572 (2016).

${ }^{18}$ L. Yan, Q. Xin, L. Du, J. Zhang, Y. Luo, Q. Wang, A. Song, Phys. Status Solidi C, 13, 618-622 (2016).

${ }^{19}$ S. M. Sze and K. K. Ng, Physics of Semiconductor Devices, third ed. (New York: John Wiley \& Sons, 2007) p.181 \& p.200.

${ }^{20}$ K. Nagashio, T. Yamashita, T. Nishimura, K. Kita, A. Toriumi, J. Appl. Phys., 110(2), 024513 (2011).

${ }^{21}$ E. Kobeda, E. A. Irene, J. Vac. Sci. Technol. B, 4(3), 720-722. (1986).

${ }^{22}$ H. Okamoto, T. B. Massalski, DIAGR Bull. Alloy. Phase. Diagr., 6, 229-235 (1985).

${ }^{23}$ R. K. Singh, D. R. Gilbert, J. Fitz-Gerald, S. Harkness, D. G. Lee, Science, 272, 396 (1996).

${ }^{24}$ I. Dökme, Ş. Altındal, Physica B: Condens. Matter, 391,59-64 (2007).

${ }^{25}$ T. Kamiya, K. Nomura, H. Hosono, J. Display Technol., 5, 462-467 (2009).

${ }^{26}$ J. H. Werner, H. H. Güttler, J. Appl. Phys., 69, 1522 (1991).

${ }^{27}$ J. Zhang, L. Zhang, X. Ma, J. Wilson, J. Jin, L. Du, Q. Xin, A. Song, Appl. Phys. Lett., 107, 093505 (2015).

${ }^{28}$ K. R. Peta, B.-G. Park, S.-T. Lee, M.-D. Kim, J.-E. Oh, T.-G. Kim, V. R. Reddy, Thin Solid Films, 534, 603-608 (2013).

${ }^{29}$ V. L. Devi, I. Jyothi, V. R. Reddy, C.-J. Choi, Phys. Status Solidi A, 209, 105-112 (2012).

${ }^{30}$ J. H. Evans-Freeman, M. M. El-Nahass, A. A. M. Farag, A. Elhaji, Microelectron. Eng., 88, 3353-3359 (2011).

${ }^{31}$ A. H. Carim, A. Bhattacharyya, Appl. Phys. Lett., 46, 872 (1985).

${ }^{32}$ Y. Yamashita, A. Asano, Y. Nishioka, H. Kobayashi, Phys. Rev. B, 59, 15872-15881 (1999).

${ }^{33}$ A. H. Carim, A. Bhattacharyya, Appl. Phys. Lett., 46, 872-874 (1985).

${ }^{34}$ R. B. Laughlin, J. D. Joannopoulos, D. J. Chadi, S. T. Pantelides, The Physics of $\mathrm{SiO}_{2}$ and its Interfaces. (New York: Pergamon, 1978) p.6. 


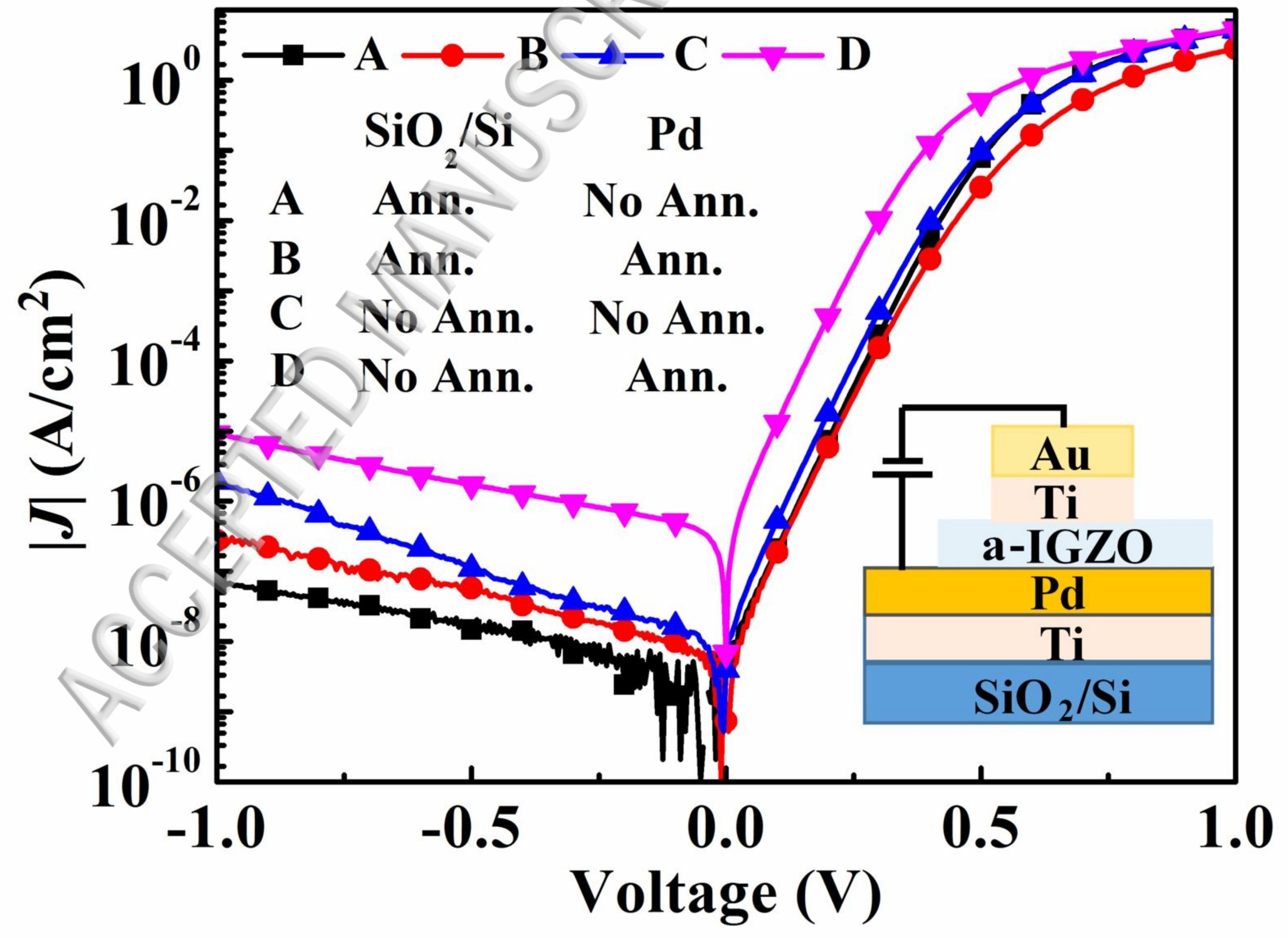




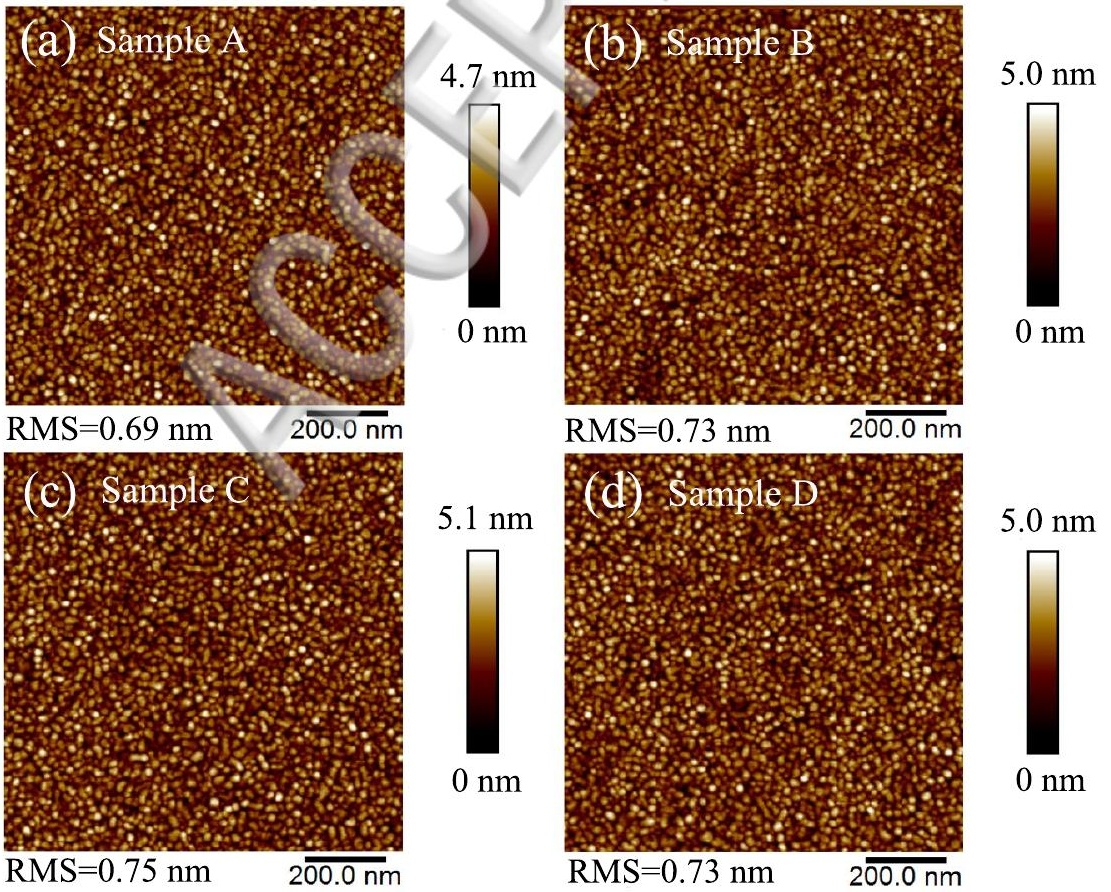



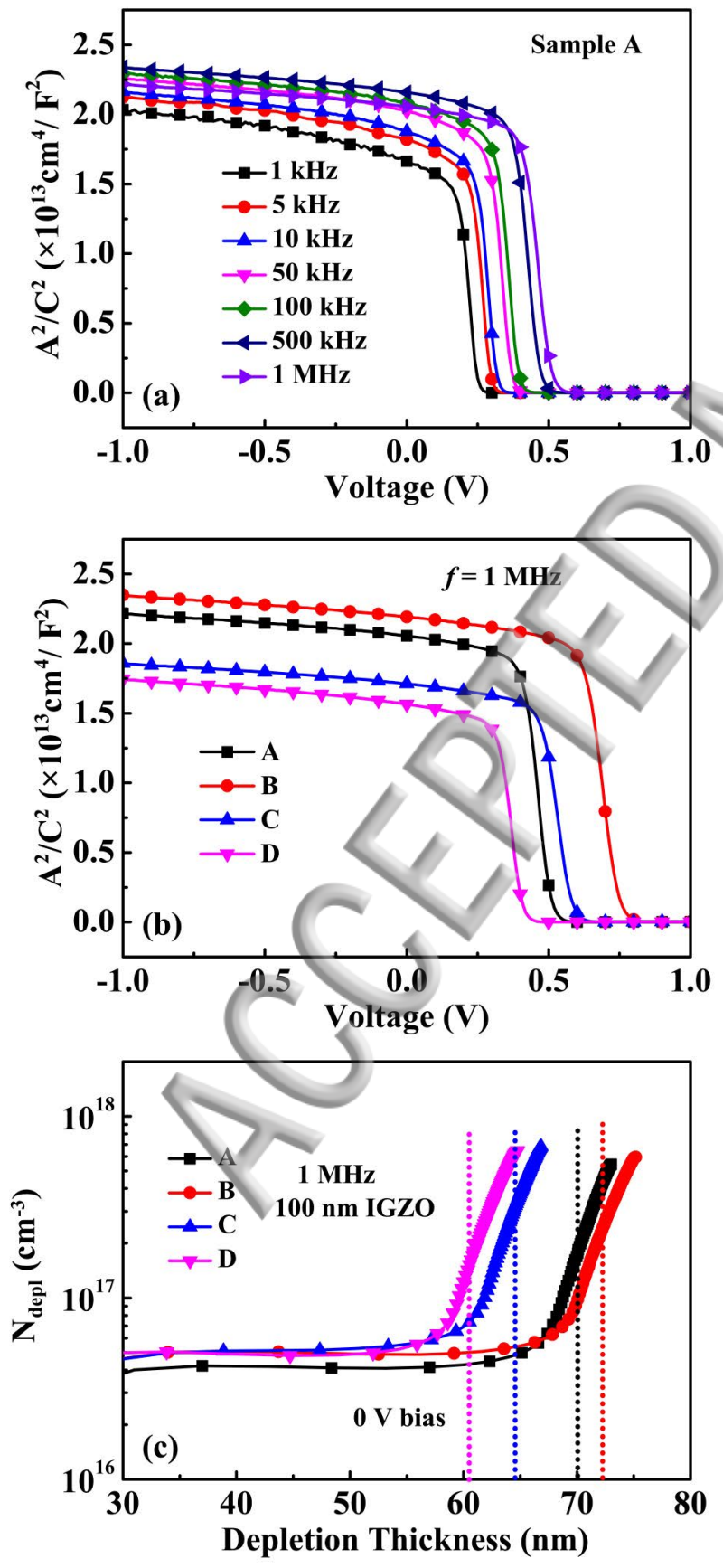